\title{
Experimental Study on the Variation Law of Excess Pore Water Pressure at the Bottom of the Foundation Pit for Excavation
}

\author{
Qizhi Hu (D), ${ }^{1}$ Qiang Zou ${ }^{1},{ }^{1}$ Zhigang Ding, ${ }^{2}$ and Zhaodong $X u^{2}$ \\ ${ }^{1}$ College of Civil Construction and Environment, Hubei University of Technology, Wuhan 430068, China \\ ${ }^{2}$ China Communication Road \& Bridge South Engineering Co.,, Ltd., Beijing 100027, China \\ Correspondence should be addressed to Qiang Zou; 101810598@hbut.edu.cn
}

Received 11 May 2020; Revised 8 October 2020; Accepted 13 October 2020; Published 29 October 2020

Academic Editor: Carlo Santulli

Copyright (c) 2020 Qizhi Hu et al. This is an open access article distributed under the Creative Commons Attribution License, which permits unrestricted use, distribution, and reproduction in any medium, provided the original work is properly cited.

The excavation unloading of deep foundation pits in soft soil areas often produces negative excess pore water pressure. The rebound deformation of soil on the excavation surface of the foundation pit can be predicted reliably through the accurate expression of relevant variation laws. In combination with the principle of effective stress and the general equation of unidirectional seepage consolidation, an equation for calculating the rebound deformation from the bottom in the process of foundation pit excavation unloading was obtained. Additionally, a triaxial unloading test was adopted to simulate the excavation unloading processes for actual foundation pit engineering. After studying the variation law of the excess pore water pressure generated by excavation unloading, it was found that the negative excess pore water pressure increased with increasing unloading rate, while the corresponding peak value decreased with increasing confining pressure. The equation for rebound calculation was verified through a comparison with relevant measured data from actual engineering. Therefore, it is considered that the equation can reliably describe the rebound deformation law of the base. This paper aims to guide the design and construction of deep foundation pits in soft soil areas.

\section{Introduction}

The engineering characteristics of structural soft clay include low strength, high sensitivity, and high water content [1], which adversely affect the construction of foundation pits, tunnels, and underground pipe corridors in soft soil areas. In deep underground engineering, passing through the soft stratum with a high clay content produces a large rebound deformation on the excavation surface, which affects normal construction. The rebound deformation of the excavation surface is closely related to the variation in the effective stress in the soil. According to the principle of effective stress, the unloading of soil under the consolidation state generates negative excess pore water pressure, which causes soil resilience. Therefore, exploring the variation law of the excess pore water pressure and predicting the rebound of the excavation surface are the keys to the deformation control and stability of the underground engineering construction process.
Many scholars have studied the variation law of excess pore water pressure and deformation characteristics of soft clay under unloading action. According to the engineering geology of the Shanghai area, Liu et al. [2,3] found that the rebound of the foundation pit was largely affected by the time factor, based on their laboratory test. Through laboratory tests, Shi and Han [4] found that the moisture absorption and rebound of soil have good adaptability and gave the analytical solution for the consolidation equation under linear unloading. Through a consolidation test for the whole process of loading and unloading, Lin and Lei [5] studied the variation law of negative excess pore water pressure with unloading quantity and unloading rate. Hao and $\mathrm{Li}$ [6] derived the anti-consolidation equation of saturated soil after unloading and analysed the generation and dissipation processes of excess pore water pressure and the development law of rebound deformation with an engineering example. The diversification of test equipment and the integration of multidisciplinary test methods have 
enabled more in-depth studies on the variation law of excess pore water pressure and the rebound.

In practical engineering application, it is often difficult to directly measure the change in excess pore water pressure. Therefore, the triaxial unloading test was carried out to simulate the excavation unloading process for foundation pit engineering to reflect the variation law of excess pore water pressure during the unloading process and the influence of unloading rate and confining pressure on the variation law of excess pore water pressure. Based on the properties of soft clay and the theory of one-dimensional seepage consolidation, the analytical solution to the excess pore water pressure was derived with a one-dimensional linear unloading equation and then compared with the corresponding test result. In addition, the equation for calculating the rebound caused by the change in excess pore water pressure was studied, and a comparison with actual monitoring was conducted. This study is expected to provide a reference for predicting the law of rebound deformation caused by excess pore water pressure during the construction of underground foundation pits in soft soil areas.

\section{One-Dimensional Consolidation Equation under Unloading Action}

\subsection{General Equation of Unidirectional Seepage} Consolidation. A saturated clay layer was selected with a thickness of $H$ and drainage on one side; i.e., the top was drained, while the bottom was not drained. The test of seepage consolidation was carried out under the action of an external load. The consolidation model is shown in Figure 1. According to the principle of effective stress, the total stress generated by the external load, $\sigma$, is borne jointly by the effective stress $\left(\sigma^{\prime}\right)$ and the pore water pressure $\left(P_{w}\right)$, while the pore water pressure includes the hydrostatic pressure $\left(\gamma_{w}\right.$ $(H-z))$ and the excess pore water pressure $(u)$. The hydrostatic pressure does not change with the consolidation process, and often, only the excess pore water pressure, which changes with consolidation degree, is considered for convenience. Therefore, it is considered that, during this process, the excess pore water pressure dissipates gradually with time, the effective stress increases, and the soil is continuously compressed until it becomes stable.

Under the condition of unidirectional seepage consolidation, a $1 \times 1$ area microunit of pore water with a thickness of $\mathrm{d} z$ at distance $z$ from the bottom surface was analysed, as shown in Figure 2. The microunit was under the joint action of three different forces: the resistance of the soil skeleton to the water flow $\left(F_{z}\right)$, the dead weight of the pore water microunit $\left(\gamma_{w} \mathrm{~d} z\right)$, and the differential water pressure between the upper and lower surfaces $\left(\left(\partial p_{w} / \partial z\right) \mathrm{d} z\right)$. Based on the continuity condition of seepage consolidation in saturated soil and the stress-strain relationship of the soil skeleton, a general equation describing the unidirectional seepage consolidation was obtained [7]:

$$
\frac{\partial^{2} u}{\partial z^{2}}+\frac{1}{C_{v}}\left(\frac{\partial \sigma}{\partial t}+\gamma^{\prime} \frac{\partial H}{\partial t}-\frac{\partial u}{\partial t}\right)+\frac{1}{k} \frac{\mathrm{d} k}{\mathrm{~d} z} \frac{\partial u}{\partial z}=0
$$

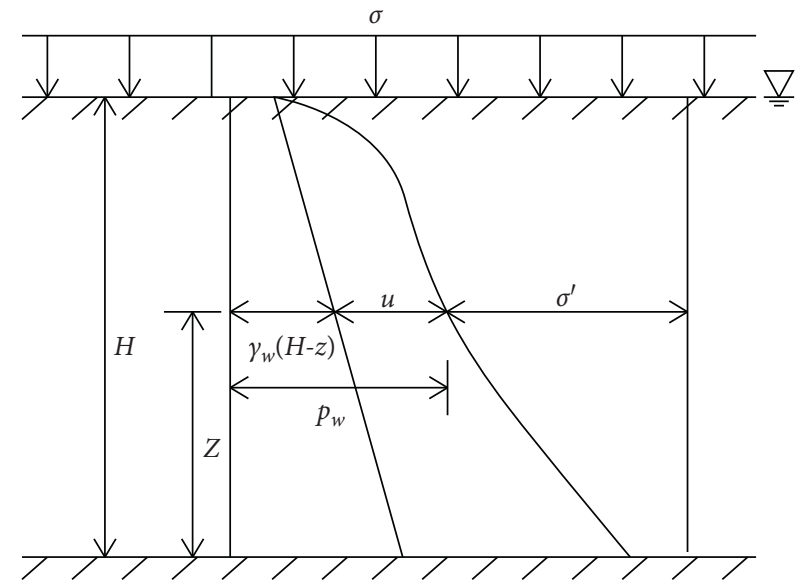

FIgURE 1: One-dimensional seepage consolidation model of saturated soil.

where $C_{v}$ is the consolidation coefficient of soil; $C_{v} C_{v}=k / m_{v} \gamma_{\mathrm{w}}$, where $k$ is the permeability coefficient; $\gamma_{\mathrm{w}}$ is the unit weight of pore water; and $m_{v}$ is the compressive modulus of elasticity. $\gamma^{\prime}$ is the submerged unit weight of soil, and $t$ is the consolidation (unloading) time.

For the equation, the influence of external load, soil layer thickness, and soil permeability on the excess pore water pressure $(u)$ was considered comprehensively. Based on the basic hypotheses of Terzaghi's one-dimensional consolidation theory, it is considered that, during the loading process, the change in thickness of the saturated clay layer $(H)$ is negligible, and the external forces cause only upward or downward seepage and compression of the soil, while the permeability coefficient does not change with depth. Thus, the differential equation for seepage consolidation in terms of the excess pore water pressure $(u)$ under the external load is as follows:

$$
C_{v} \frac{\partial^{2} u}{\partial z^{2}}=\frac{\partial u}{\partial t}-\frac{\partial \sigma}{\partial t}
$$

\subsection{Derivation of Equations for Pore Water Pressure Response} and Rebound. During the foundation pit excavation, the decreasing process for the overburden pressure of the soil at the bottom of the pit can be taken as a decreasing process for $\sigma_{z, t}$, the applied load in the one-dimensional seepage consolidation model. Therefore, $R(t)$, the unloading rate, and $C_{\mathrm{ve}}$, the anti-consolidation coefficient, are introduced, and equation (2) can be modified as

$$
C_{\mathrm{ve}} \frac{\partial^{2} u(z, t)}{\partial z^{2}}=\frac{\partial u(z, t)}{\partial t}-R(t)
$$

where $C_{\mathrm{ve}}$ is the anti-consolidation coefficient; $u(z, t)$ is the excess pore water pressure function of depth and time; and $R(t)$ is the unloading rate, indicating the change in external load with unloading time. The excavation unloading process of the foundation pit is a multi-stage linear unloading process [8], which can be simplified to a single linear 


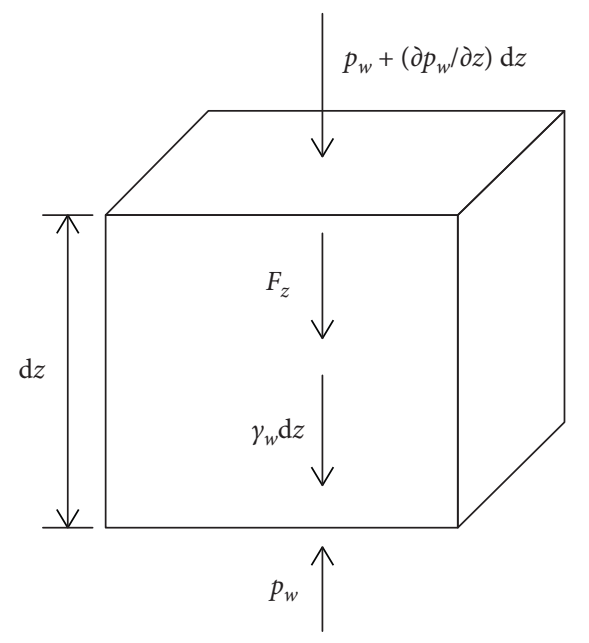

FIgURE 2: Unidirectional force diagram of the microunit with thickness of dz.

unloading process for research. In this process, the change in external load with time is shown in Figure 3.

According to the curve of the vertical stress $\left(\sigma_{t}\right)$ in different stages, the unloading rate $(R(t))$ can be expressed as

$$
R(t)= \begin{cases}\frac{\sigma_{n}-\sigma_{1}}{t_{1}}, & 0 \leq t \leq t_{1}, \\ 0, & t_{1} \leq t .\end{cases}
$$

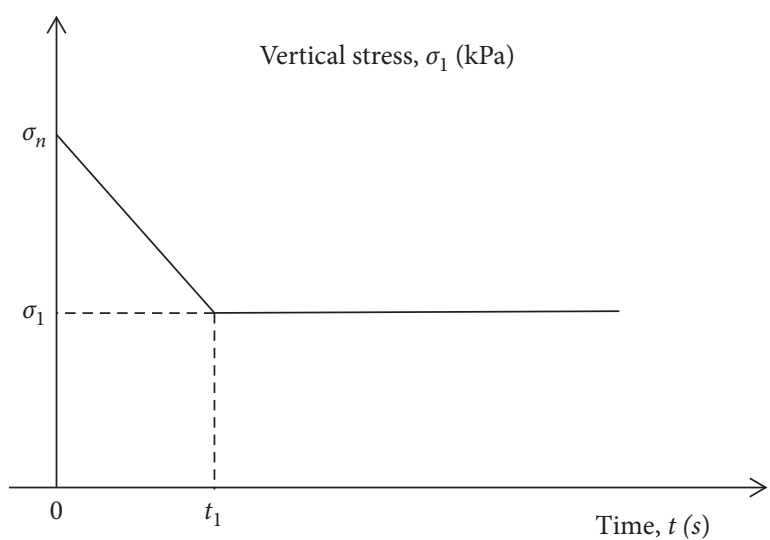

FIgURE 3: Load-time curve in the unloading process.

Equation (4) can be substituted into equation (3), and the following boundary conditions of equation (3) can be introduced:

(1) $t=0,0 \leq z \leq H, u=u_{0}=\sigma$,

(2) $t>0, z=0, u=0$,

(3) $t>0, z=H, \partial u / \partial t=0$.

Using separation of variables and the Fourier series method, the analytical solution, $u(z, t)$, of equation (3) for the excess pore water pressure is as follows [6]:

$$
u(z, t)= \begin{cases}-\frac{16\left(\sigma_{n}-\sigma_{1}\right)}{T_{\mathrm{ve} 1} \pi^{3}} \sum_{n=1,3,5 \ldots}^{\infty} \frac{1}{n^{3}} \sin \frac{n \pi z}{2 H}\left[1-\exp \left(-\frac{n^{2} \pi^{2}}{4} T_{\mathrm{ve}}\right)\right], & 0 \leq t \leq t_{1}, \\ -\frac{16\left(\sigma_{n}-\sigma_{1}\right)}{T_{\mathrm{ve} 1} \pi^{3}} \sum_{n=1,3,5 \ldots}^{\infty} \frac{1}{n^{3}} \sin \frac{n \pi z}{2 H}\left[\exp \left(\frac{n^{2} \pi^{2}}{4} T_{\mathrm{ve} 1}\right)-1\right] \cdot \exp \left(-\frac{n^{2} \pi^{2}}{4} T_{\mathrm{ve}}\right), & t_{1}<t,\end{cases}
$$

where $T_{\mathrm{ve}}=\left(C_{\mathrm{ve}} t / H^{2}\right)$ and $T_{\mathrm{vel}}=\left(C_{\mathrm{ve}} t_{1} / H^{2}\right)$.

According to equation (5), the excess pore water pressure caused by soil unloading is jointly influenced by $R(t)$, the unloading rate $C_{\mathrm{ve}}$, the anti-consolidation coefficient, and the unloading amount. In the unloading process, the generation and dissipation of negative excess pore water pressure lead to the soil rebound of moisture absorption. Based on the principle of effective stress and the relationship between the rebound and the effective stress, the equation for calculating the rebound at the bottom caused by the change in the excess pore water pressure is obtained as follows:

$$
S(t)=-\frac{H}{E_{e}}\left[\sigma(t)-\gamma_{w} z-u(z, t)\right]
$$

where $E_{e}$ is the resilient modulus, which is 5-10 times $E_{s}$, the compression modulus.

\section{Triaxial Unloading Test}

The foundation pit excavation has a vertical unloading effect on the pit soil. Thus, the unloading of soil at different depths in the pit can be equivalent to constant confining pressure and unloading of axial pressure in the triaxial unloading test to justify the above equation. A deep foundation pit engineering for a subway station was selected for the study, and the engineering site was of soft clay. After field sampling, the variation law concerning excess pore water pressure and the rebound in the axial unloading process of the samples were explored through the triaxial unloading test.

3.1. Instruments. The TSZ series of fully automatic triaxial instruments was adopted. The test system included a triaxial test chamber, a confining pressure controller, and a backpressure controller. The tensile unloading was realized by 
lowering the base, as shown in Figure 4. The test process was controlled by a computer. The test data were collected and recorded by the built-in software of the instrument. The TSZ series of fully automatic triaxial instruments can perform conventional stress-strain unlimited tests; compression and shear tests of UU, CU, and CD; K0 consolidation tests; static lateral pressure coefficient tests; and various stress paths of triaxial tests.

3.2. Sampling and Sample Preparation. To study the variation law concerning excess pore water pressure and rebound in soil at different depths and different unloading levels, undisturbed soil samples were cut at each of the three layers of the excavation surface in the middle of the subway station foundation pit excavation for the triaxial unloading test. The sampling location and soil layer information are shown in Figure 5.

A comparison with the geological survey report after field sampling found that the soil samples were all clay in a plastic state-i.e., a medium compressibility soil with a buried depth of $2-24 \mathrm{~m}$. The physical and mechanical properties of the samples measured according to the "Standard for Soil Test Methods" are shown in Table 1.

Considering the influence of soil structure in the test, the intact soil samples were put into the sampling cylinder and kept intact by a wax seal. During the transportation and preparation processes, the disturbance to the soil sample was minimized, so that the engineering practice could be effectively simulated during the test.

According to the "Standard for Soil Test Methods" and the testing requirements of the fully automatic triaxial instruments, undisturbed soil was cut into soil samples $80 \mathrm{~mm}$ in height and $39.1 \mathrm{~mm}$ in diameter with a soil cutting knife. The sample was loaded on the saturator dedicated to the saturation test and then put into the vacuum cylinder. The vacuum pump and the vacuum cylinder were connected, and the vacuum pump was started for evacuating saturation. When the reading of the vacuum pressure gauge was close to $1 \mathrm{~atm}$, the vacuum pump and vacuum pump valve on the vacuum cylinder were closed. The water valve was opened so that clean water was slowly injected into the vacuum cylinder, and the evacuating saturation of samples was completed using the pressure difference between the inside and outside of the samples. The device for evacuating saturation is shown in Figure 6.

3.3. Test Protocol. In the study of the variation law of excess pore water pressure at different positions of the foundation pit, the actual stress path of soil is very complicated due to the influence of residual stress at the position of soil, the unloading ratio, various supporting systems, and reinforcement measures. To facilitate analysis and research, the stress path was simplified [9]. In practical engineering, the overburden pressure of the samples decreases with increasing excavation of the upper soil, and the horizontal stress is generally unchanged. In other words, for the stress path of the soil at the excavation surface during the excavation process, the horizontal stress is unchanged, while the

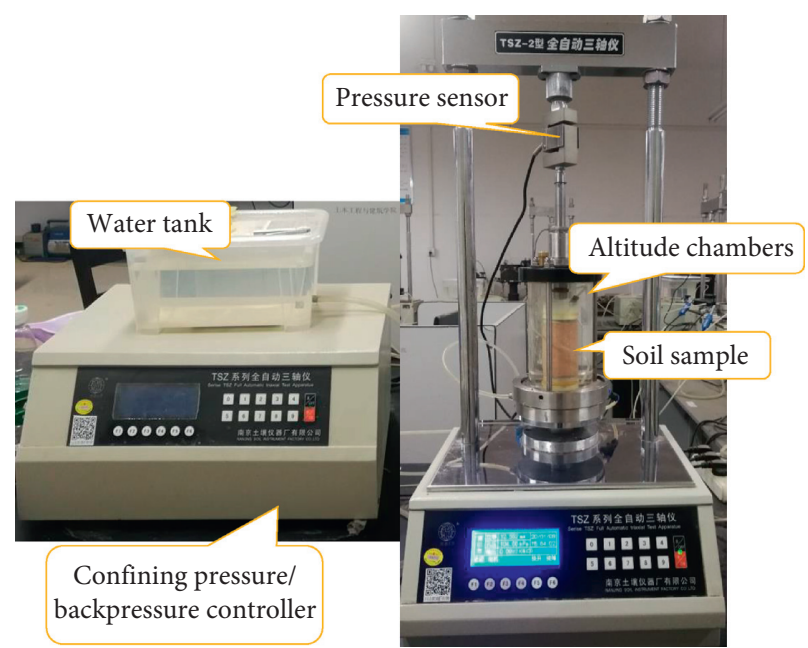

FIGURE 4: TSZ series of fully automatic triaxial instrument.

vertical stress is decreased. The unloading stress path is $\mathrm{OAB}$ in Figure 7.

In the test, the samples were divided into groups $\mathrm{A}, \mathrm{B}$, and $C$ by sampling depth. A total of nine samples (three in each group) were prepared and numbered as follows: A1, $\mathrm{A} 2$, and $\mathrm{A} 3$; B1, B2, and B3; and $\mathrm{C} 1, \mathrm{C} 2$, and C3. During the excavation unloading of the foundation pit, the soil or buildings around the pit always have a lateral extrusion effect on the soil in the pit. Thus, we assume that for each soil layer, as a vertical excavation unloading is performed, the horizontal stress of the corresponding soil layer will be unchanged:

$$
\sigma_{c x}=\sigma_{c y}=K_{0} \sigma_{c z}
$$

where $K_{0}$ is the coefficient of earth pressure at rest, which can be selected according to Figure 5, and $\sigma_{c z}$ is the geostatic stress at each excavation surface.

Based on the actual site parameters of the foundation pit and the depth of each excavation surface, the natural stress states of the nine samples before excavation were calculated, as shown in Table 2.

3.3.1. Consolidation of Sample $K_{0}$. To simulate the change in the actual stress state of soil during excavation, the $K_{0}$ consolidation function of the triaxial instrument was used to apply three-dimensional stress as shown in Table 2 (actually two-dimensional stress in the conventional triaxial test: axial pressure and confining pressure) to the test samples for the $K_{0}$ consolidation test so that the soil samples returned to the natural stress state before excavation.

The saturated samples were loaded according to the operation procedure of the instrument. After completion of the sample loading, the test was adjusted to the $K_{0}$ consolidation mode through the computer, and the three-dimensional stress was applied according to the stress levels in Table 2. Meanwhile, the drainage valve for pore water was opened for $24 \mathrm{~h}$ of consolidation. 


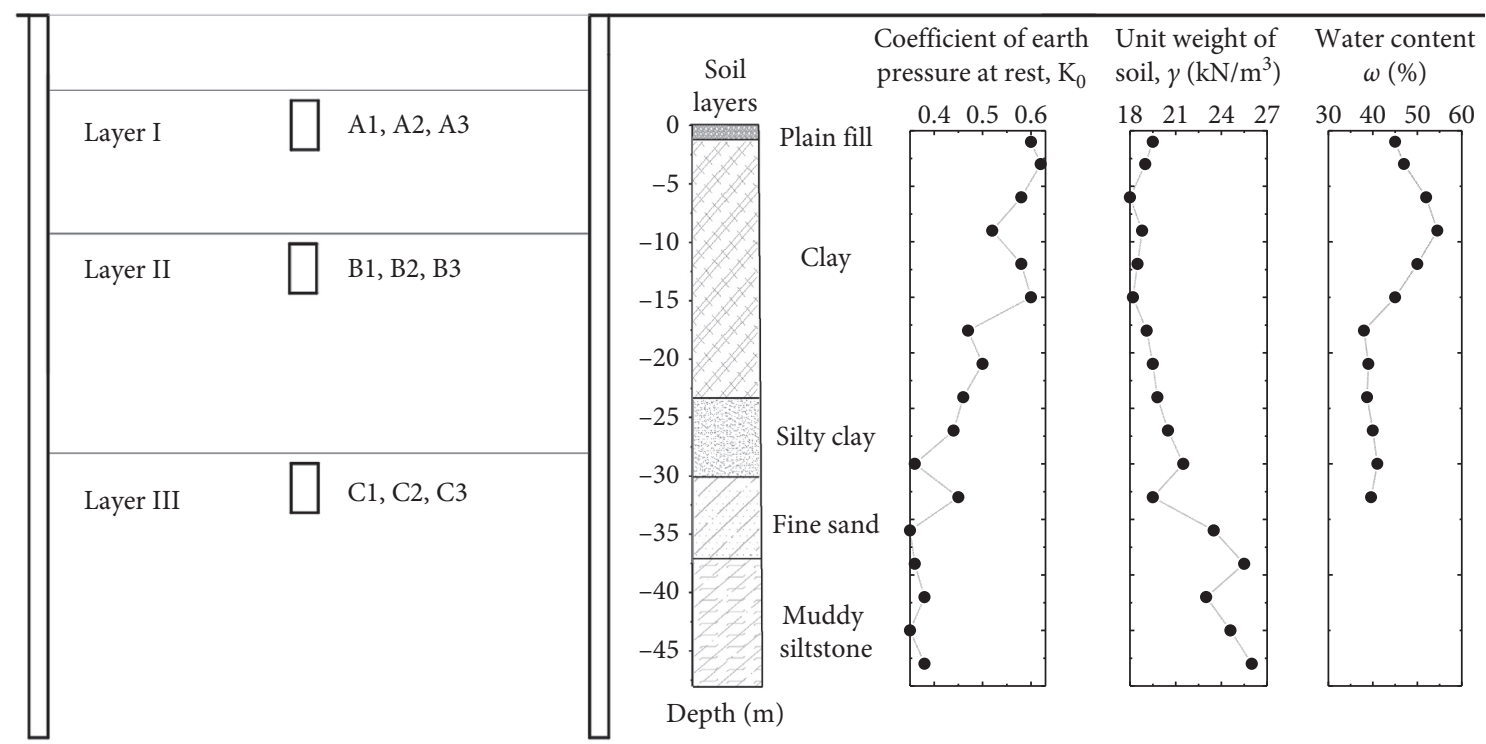

FIGURE 5: Schematic diagram of sampling location and soil layer information.

TABLE 1: The physical and mechanical properties of soft soil samples.

\begin{tabular}{lccccc}
\hline Water content $\omega(\%)$ & Natural density $\rho\left(\mathrm{kg} / \mathrm{m}^{3}\right)$ & Relative density & Porosity ratio $e$ & Liquid limit $w_{L}(\%)$ & Plastic limit $w_{P}(\%)$ \\
\hline 48.5 & 1.88 & 2.75 & 0.94 & 33.1 & 21.2 \\
\hline
\end{tabular}

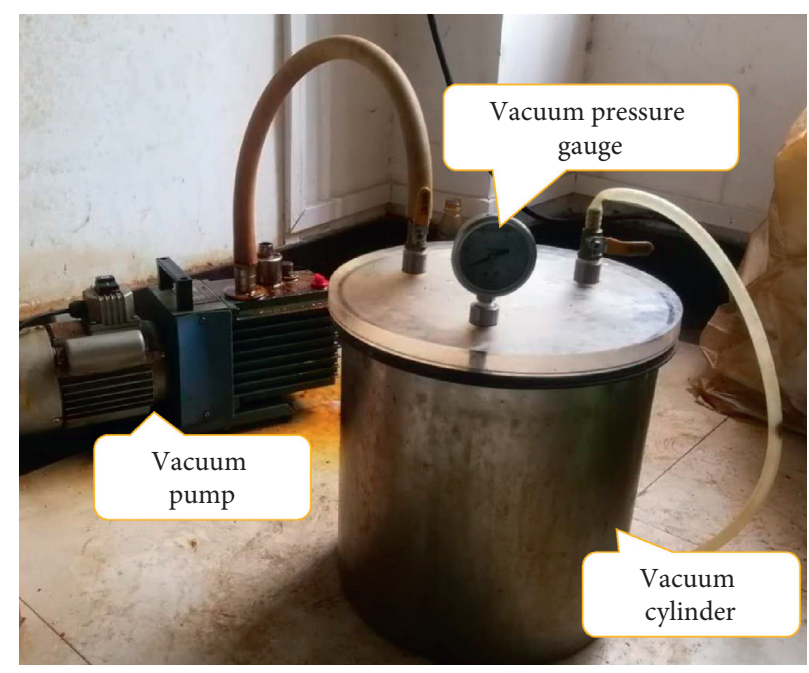

FIgURE 6: The device for evacuating saturation.

3.3.2. Vertical Unloading. After $24 \mathrm{~h}$ of consolidation for the test samples, the drainage valve was closed, and the gauge for pore water pressure was set to zero. The sample height was recorded at this time, and the stress levels of the axial pressure and confining pressure were observed for consistency with the vertical stress and horizontal stress in Table 2 . The pressure chamber base was slowly dropped to gradually reduce the axial stress. At the same time, the change process of vertical stress was automatically recorded over time by the computer, and the change in pore water pressure in the samples was recorded over time with a pore water pressure gauge.
To study the influence of the excavation unloading rate [10] on pore water pressure, different unloading rates were adopted in this test. The details are shown in Table 3.

\section{Test Results and Analysis}

4.1. Development Law of Excess Pore Water Pressure. Through the triaxial unloading test, the curves of excess pore water pressure with time under different unloading rates and different confining pressures were obtained, as shown in Figures 8-10. According to the figures, the values of excess 


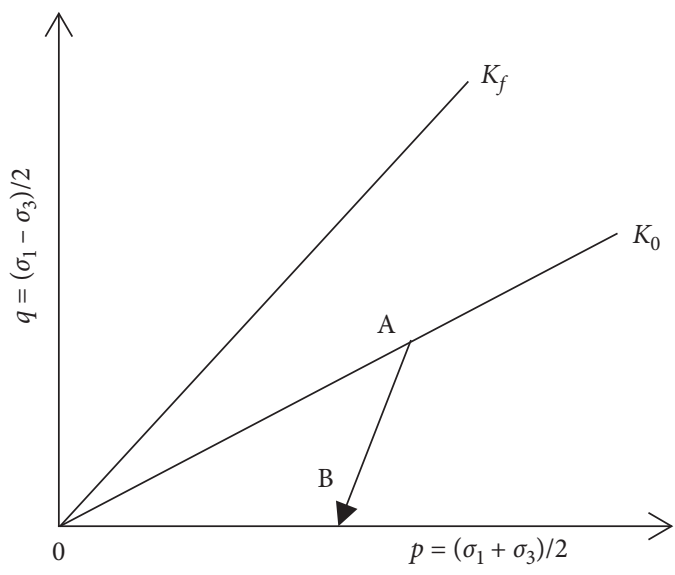

FIGURE 7: The schematic diagram for the soil stress path during foundation pit excavation.

TABLE 2: Natural stress levels of the samples.

\begin{tabular}{lccc}
\hline No. & $\begin{array}{c}\text { Sampling depth } \\
(\mathrm{m})\end{array}$ & $\begin{array}{c}\text { Vertical stress } \\
(\mathrm{kPa})\end{array}$ & $\begin{array}{c}\text { Horizontal stress } \\
(\mathrm{kPa})\end{array}$ \\
\hline A1, A2, & -4.7 & 107 & 63 \\
A3 & & 221 & 121 \\
B1, B2, & -12 & & \\
B3 & & 412 & 219 \\
C1, C2, & -22.8 & & \\
C3 & & & \\
\hline
\end{tabular}

TABLE 3: Unloading rates of different samples.

\begin{tabular}{lc}
\hline No. & Unloading rate $(\mathrm{mm} / \mathrm{min})$ \\
\hline A1, B1, C1 & 0.08 \\
A2, B2, C2 & 0.06 \\
A3, B3, C3 & 0.04 \\
\hline
\end{tabular}

pore water pressure caused by unloading were all negative. With time, they first showed a downward trend and then an upward trend. At the same time, the change in the values had a certain correlation with the confining pressure and unloading rate.

\subsubsection{Influence of Unloading Rate on the Negative Excess Pore} Water Pressure. To facilitate analysis, the confining pressure of $121 \mathrm{kPa}$ was taken as an example. The peak value of negative excess pore water pressure in the unloading process was selected as the reference point, and the curve of excess pore water pressure with unloading rate was obtained under confining pressure of $121 \mathrm{kPa}$, as shown in Figure 11 .

As shown in Figure 11, the faster the unloading rate, the greater the negative excess pore water pressure, and the farther the curve of the corresponding excess pore water pressure in Figures 8-10 moves away from the horizontal axis. This indicates that the unloading rate influences the dissipation rate of the negative excess pore water pressure and that the relevant variation law is obviously correlated with time. A slow unloading rate means that the time for

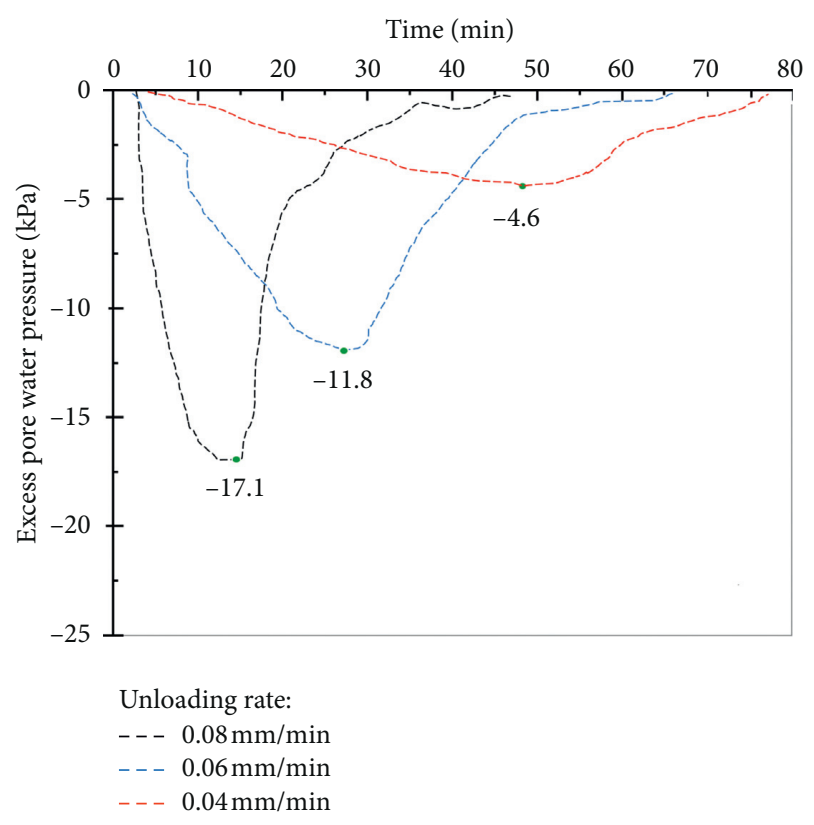

Figure 8: Curves of excess pore water pressure values with time under different unloading rates at a confining pressure of $63 \mathrm{kPa}$.

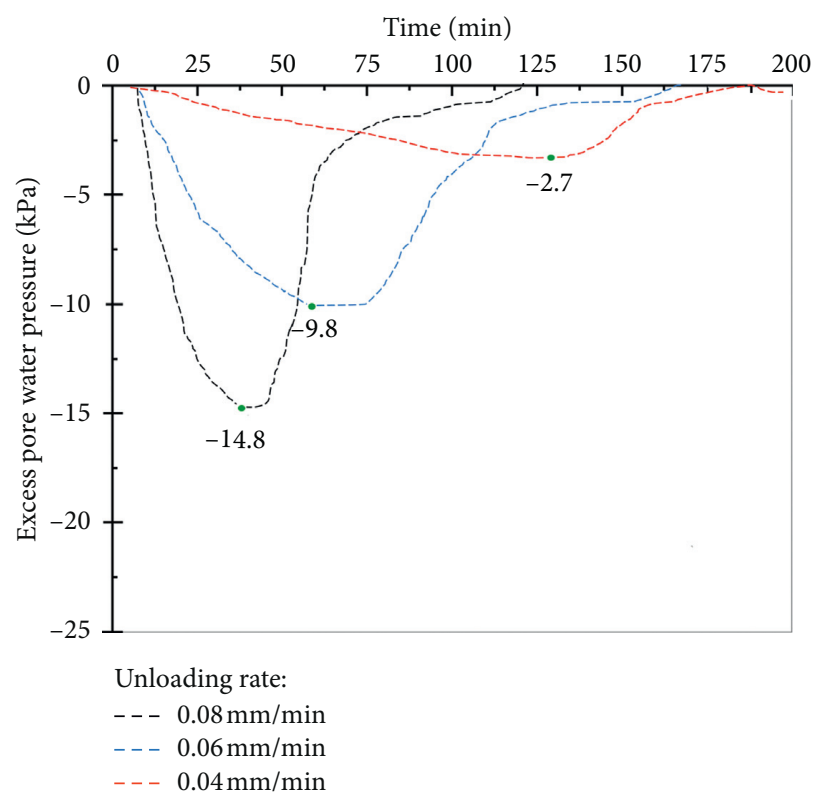

FIgURE 9: Curves of excess pore water pressure values with time under different unloading rates at a confining pressure of $121 \mathrm{kPa}$.

dissipation of negative excess pore water pressure generated through unloading is long, so the peak value of the negative excess pore water pressure is relatively low.

\subsubsection{Variation Characteristics of Negative Excess Pore Water} Pressure under Different Confining Pressures. In excavation engineering, larger negative excess pore water pressure tends to cause larger soil deformation. Therefore, the relationship between the peak value of negative excess pore water pressure and the confining pressure was summarized based 


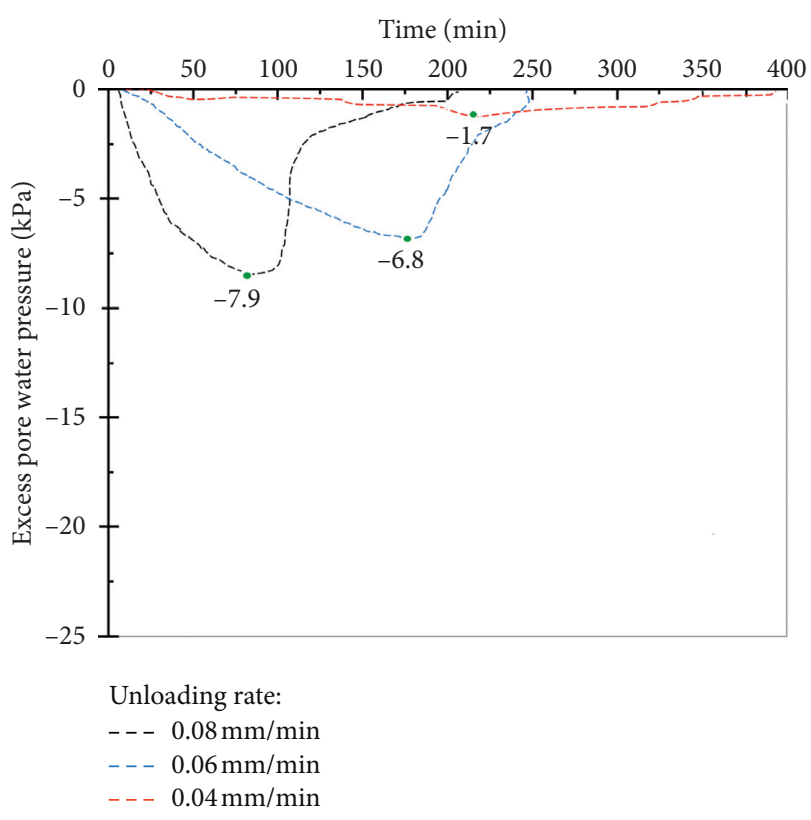

Figure 10: Curves of excess pore water pressure values with time under different unloading rates at a confining pressure of $219 \mathrm{kPa}$.

on unloading rates of $0.04,0.06$, and $0.08 \mathrm{~mm} / \mathrm{min}$ in the unloading test, as shown in Figures 8-10 and 12.

According to Figure 12, the peak value of negative excess pore water pressure in the test was inversely proportional to confining pressure at any unloading rate. The larger the confining pressure, the deeper the foundation pit, reflecting that the negative excess pore water pressure was inversely proportional to the depth within the sample depth range.

4.1.3. Comparison between Experimental Data and Theoretical Values. To study the accuracy of $u(z, t)$, the analytical solution for excess pore water pressure obtained under a linear unloading condition, in describing the variation law of excess pore water pressure, equation (5) was substituted into MATLAB for programming. The depth $(H)$ was selected according to Table 2. $C_{\mathrm{ve}}$, the anti-consolidation coefficient, was $1.39 \times 10^{-7} \mathrm{~m}^{2} / \mathrm{s}$. The remaining parameters were taken as variables. Thus, the theoretical value of excess pore water pressure under the linear unloading condition was calculated. Because a large negative excess pore water pressure might cause a large rebound of soil, the calculated value of excess pore water pressure under confining pressure of $63 \mathrm{kPa}$ and unloading rate of $0.08 \mathrm{~mm} / \mathrm{min}$ was selected for comparison with the experimental value of excess pore water pressure, as shown in Figure 13.

According to the figure, the theoretical value curve was in good agreement with the experimental value curve in the test. For both curves, the negative excess pore water pressure generated by unloading increased at first and then decreased with time and reached the peak approximately at the end of unloading. Since the triaxial unloading test effectively simulated the foundation pit excavation unloading, the agreement between the theoretical value and the experimental value also indicates that $u(z, t)$, the analytical solution

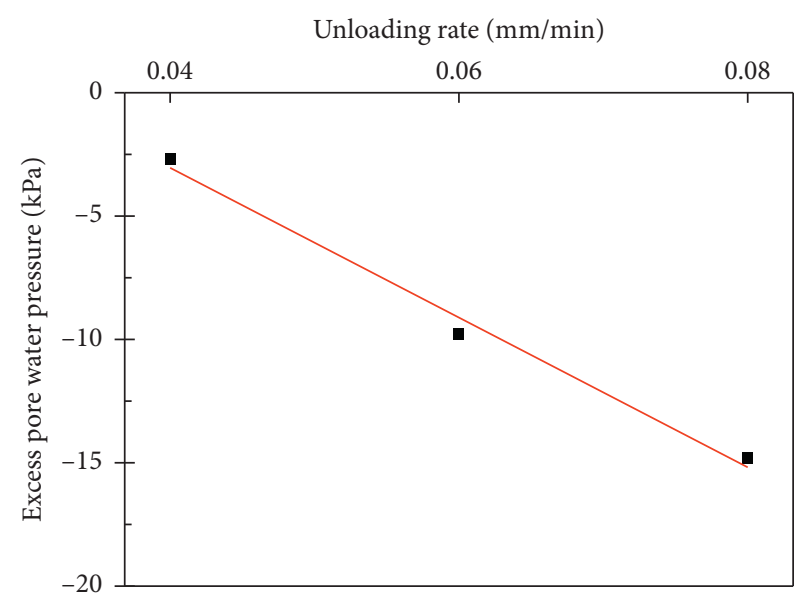

FIgURE 11: Curve of excess pore water pressure with unloading rate under confining pressure of $121 \mathrm{kPa}$.

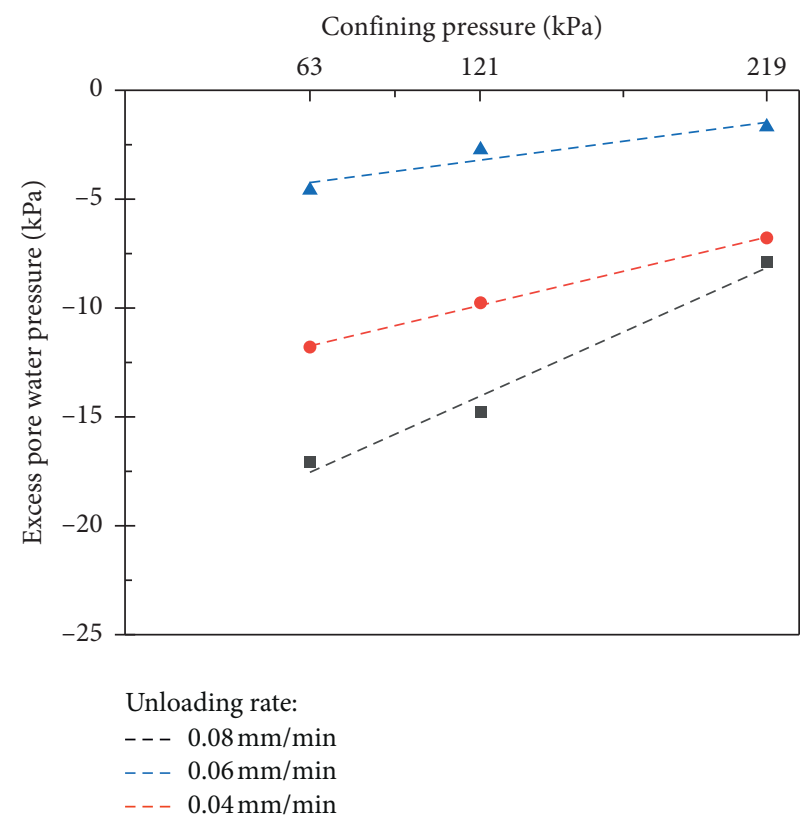

FIGURE 12: Curves of peak value of excess pore water pressure with confining pressure.

of excess pore water pressure under the linear unloading condition, can effectively reflect the variation law of excess pore water pressure during the foundation pit excavation unloading process.

4.2. Analysis on Unloading Rebound and Deformation Samples. During the excavation unloading process of the foundation pit, the generation and dissipation of negative excess pore water pressure greatly influence the rebound of soil. To study the characteristics of rebound deformation for the test soil at different depths, the consolidation and unloading processes of the test samples were plotted as a curve of void ratio $e$ against the logarithm of axial stress, as shown in Figure 14. 


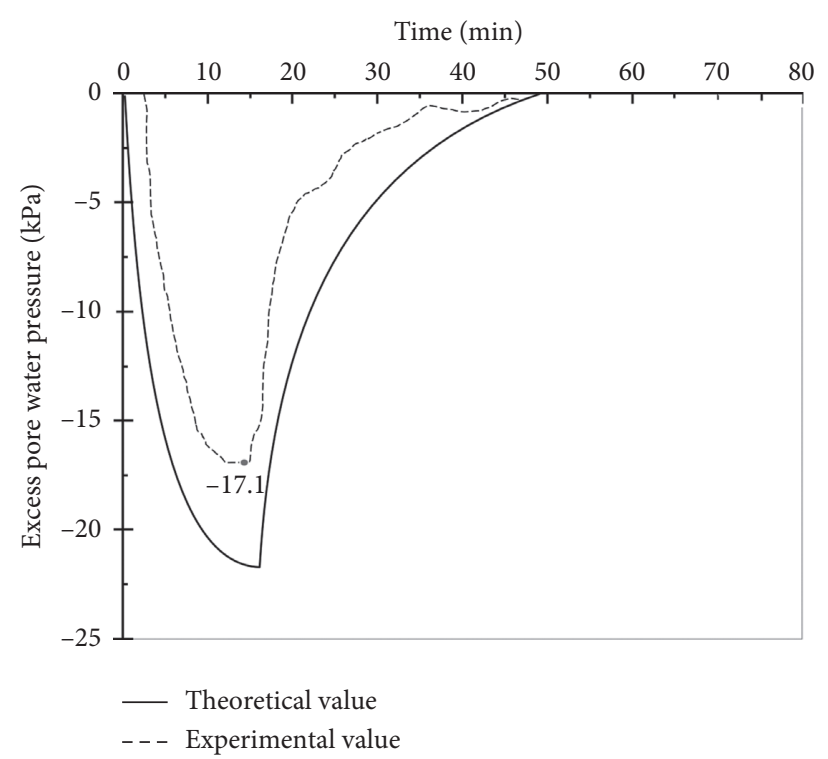

Figure 13: Comparison between theoretical and experimental values of excess pore water pressure.

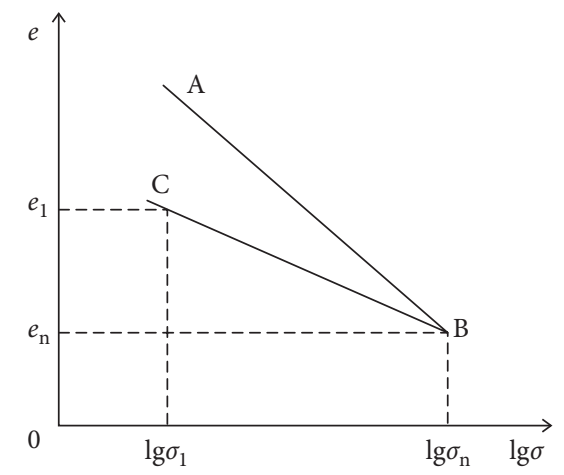

Figure 14: Rebound curve of soil (BC segment).

The BC segment in Figure 14 represents the unloading process of the soil. In this process, the porosity ratio increased, the excess pore water pressure decreased, and obvious volume deformation of the soil appeared. Typical sample diagrams in the triaxial test were selected at three different time nodes corresponding to "Before consolidation (A)," "Before unloading (B)," and "Completion of unloading (C)," as shown in Figure 15.

As shown in the figure, after $24 \mathrm{~h}$ of consolidation, a certain amplitude of the bulge appeared on the surface of the sample before unloading; after unloading, the bulge amplitude on the surface of the sample was reduced. However, several obvious folds appeared on the rubber membrane. This indicates that there was an axial rebound in the unloading process for the sample, but the volume state before axial pressure was applied was not recovered.

To quantitatively analyse the deformation characteristics of samples at different depths during the test, based on the basic hypotheses of Terzaghi's one-dimensional consolidation theory, it is considered that both soil particle and pore water are incompressible. Therefore, during the observation time, the volume change caused by the rebound deformation of the test soil sample is equal to the volume of pore water entering the soil. Thus, the axial rebound of the sample in the unloading process is determined. The rebound deformation values of the samples measured in the test were plotted with different depths, and then a corresponding linear fitting curve was obtained, as shown in Figure 16.

As shown in Figure 16, the rebound deformation of soil gradually decreased with the increase in foundation pit depth, which reflected the effect of high confining pressure-i.e., inhibiting the generation of negative excess pore water pressure and thus reducing the rebound deformation of soil.

4.3. Mechanism for the Generation of Negative Excess Pore Water Pressure. In the process of soil excavation unloading in soft soil areas, the variation law of excess pore water pressure is different from other soil types [11]. This is mainly because a layer of adsorbed water [12,13] has been formed on the surface of clayey soil particles common in soft soil areas, as shown in Figure 17. This makes clayey soil drain water under the compression condition and absorb water under the decompression condition.

During the unloading process, both the stresses borne by the soil particles and the interaction between particles are gradually weakened. This increases the thickness of the adsorbed water layer on the surface of clayey soil particles and makes the sample absorb a large amount of water from the outside and gradually form a negative excess pore water pressure. In the unloading test under high confining pressure, there was a great interaction force caused by confining pressure between the clayey soil particles. Because of this, there was a substantial extrusion effect for the adsorbed water layer on the surface of the soil particles. This limited the variation range for the thickness of the adsorbed water layer, so a relatively low negative excess pore water pressure was produced. For this, the peak value of negative excess pore water pressure decreased with the increase in confining pressure. In addition, the high unloading rate also means that the interaction force between particles can be weakened rapidly in a short time, which also leads to a rapid increase in the thickness of the adsorbed water layer and the formation of large negative excess pore water pressure.

Additionally, the adsorbed water layer formed by unloading and moisture absorption of clayey soil particles has properties similar to a solid state, which enhance both the interaction between soil particles and the effective stress and thus cause the rebound deformation of clayed soils.

\section{Analysis on Actual Measurement Engineering}

To justify the equation for calculating the rebound at the bottom of the pit, the corresponding curve was compared with the deformation data of the subway station foundation pit. The data were measured by the first-line construction workers on-site and thus can accurately reflect the engineering practice. The rebound deformation data were selected from five different measurement points along the 


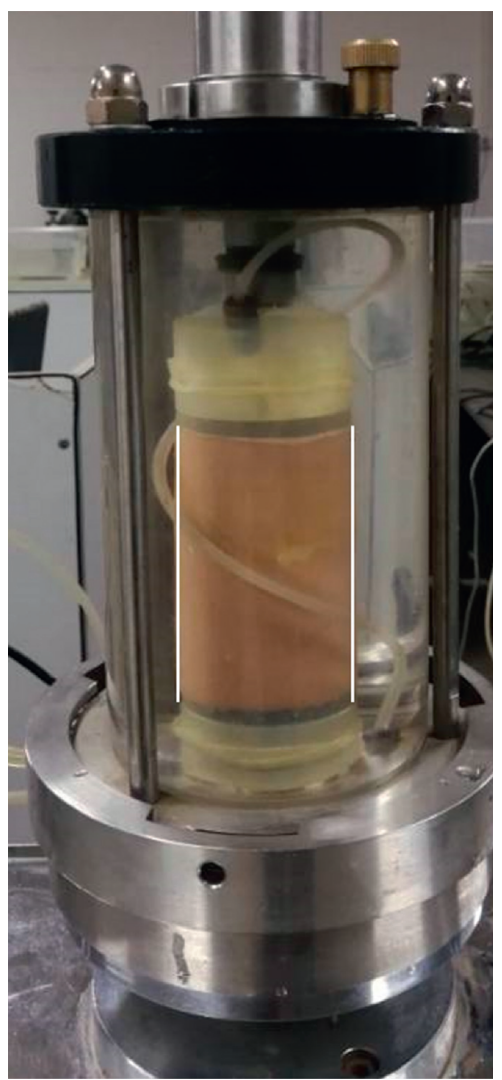

(a)

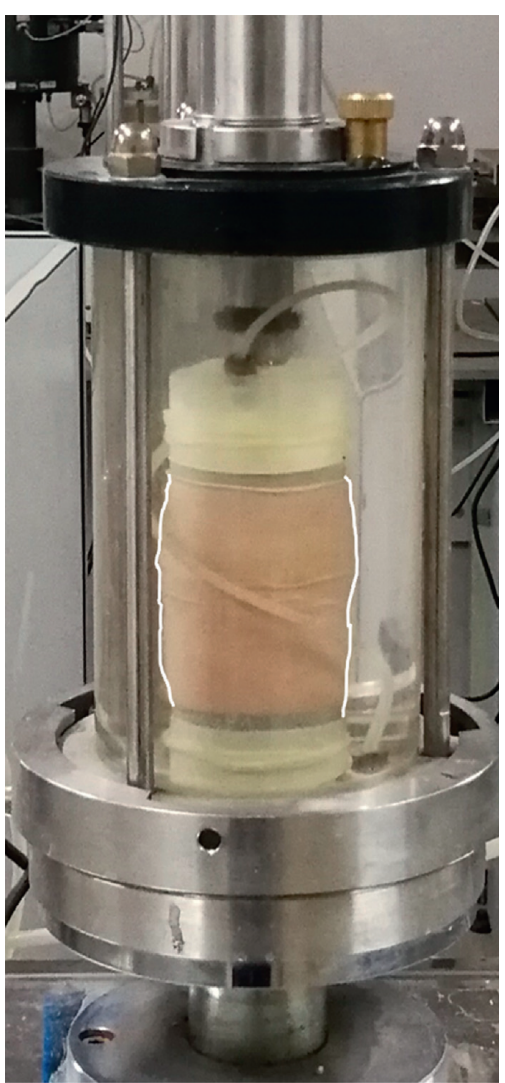

(b)

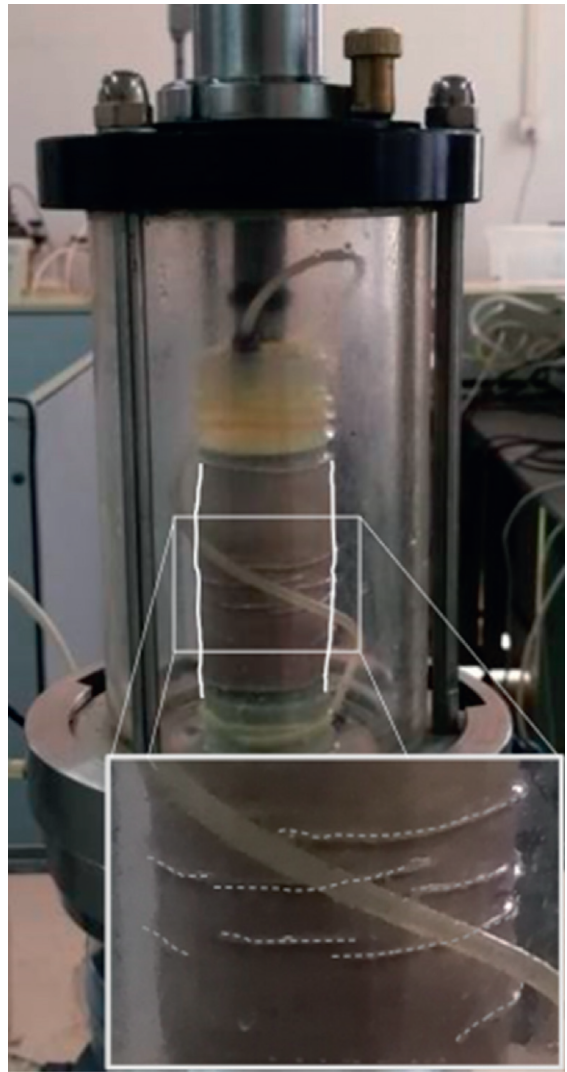

(c)

FIgURE 15: Typical schematic diagrams for samples: (a) Before consolidation. (b) Before unloading. (c) Completion of unloading.

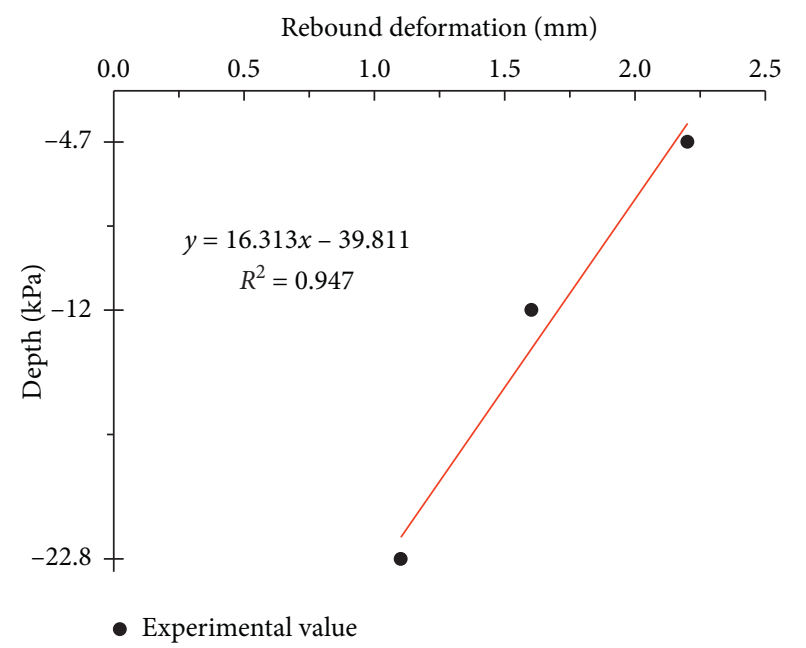

FIGURE 16: Curve of rebound deformation in the test with depth.

length of the bottom of the foundation pit for the subway station, as shown in Figure 18.

Excess pore water pressure with regard to three different unloading rates at the bottom of the foundation pit with a horizontal stress of $219 \mathrm{kPa}$ was selected for substitution into $S(t)$ to calculate the rebound and then imported into

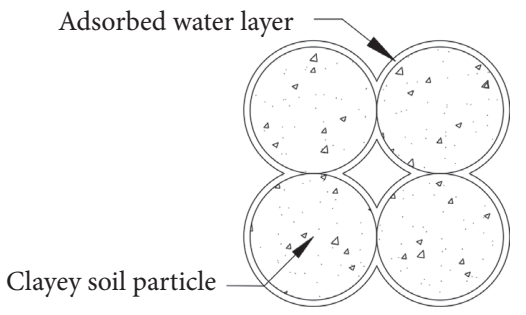

Figure 17: Adsorbed water layer on the surface of clayey soil particles.

MATLAB for programming. The curve of theoretical values of rebound with time was obtained. The values for settlement changes measured at the above five points were averaged. The average values were compared with theoretical values in the curve, as shown in Figure 18.

According to Figure 19, the measured values and theoretical values of rebound are in good agreement regarding the variation law, indicating that $S(t)$ for calculating the rebound derived in the paper satisfies the requirements for predicting the base rebound. In addition, the later measured values were generally higher than the theoretical values, which indicated that the negative excess pore water pressure of the soil at the bottom of the pit had been fully dissipated by that time. Thus, the difference between the two was 


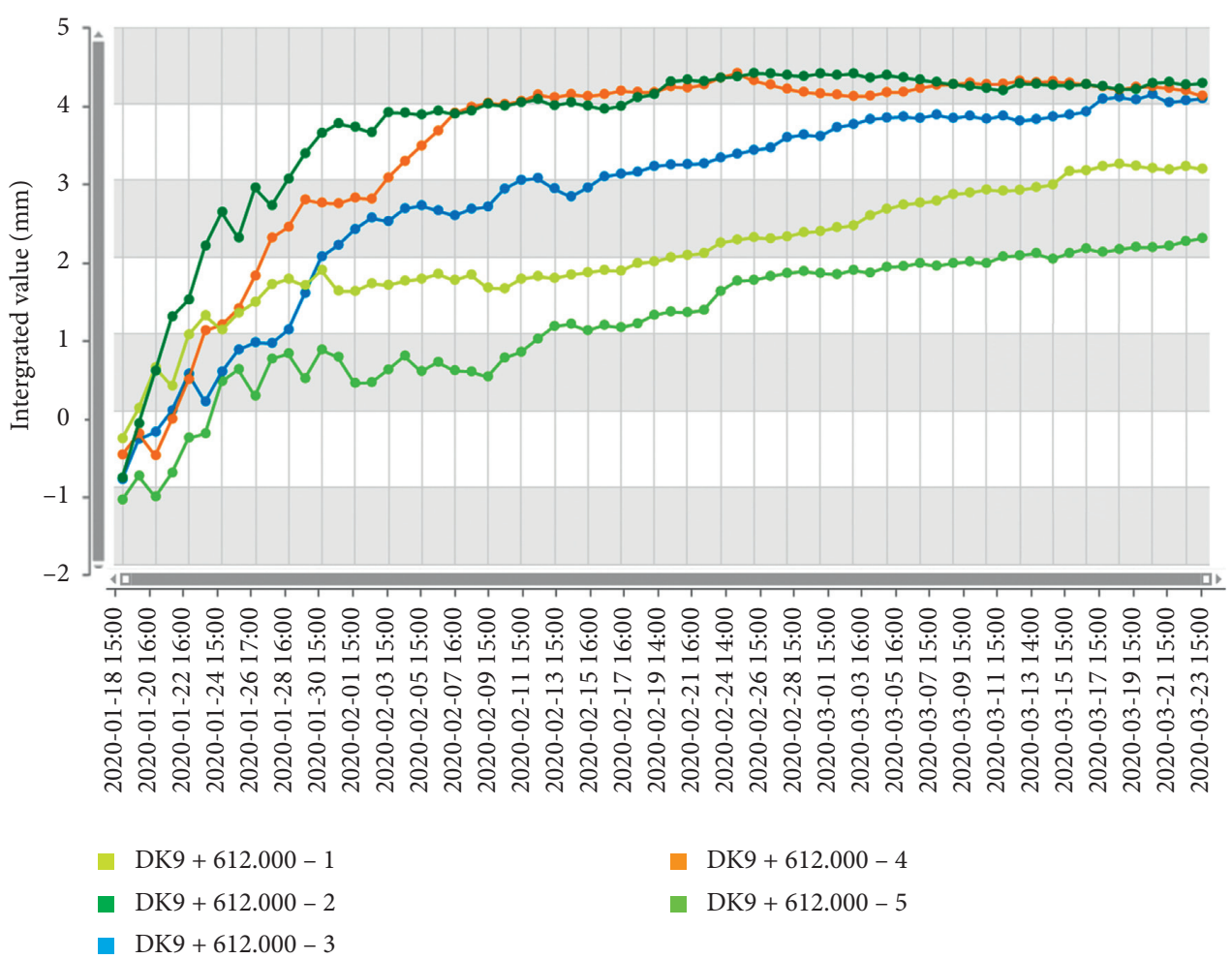

Figure 18: Rebound deformation at the bottom of foundation pit.

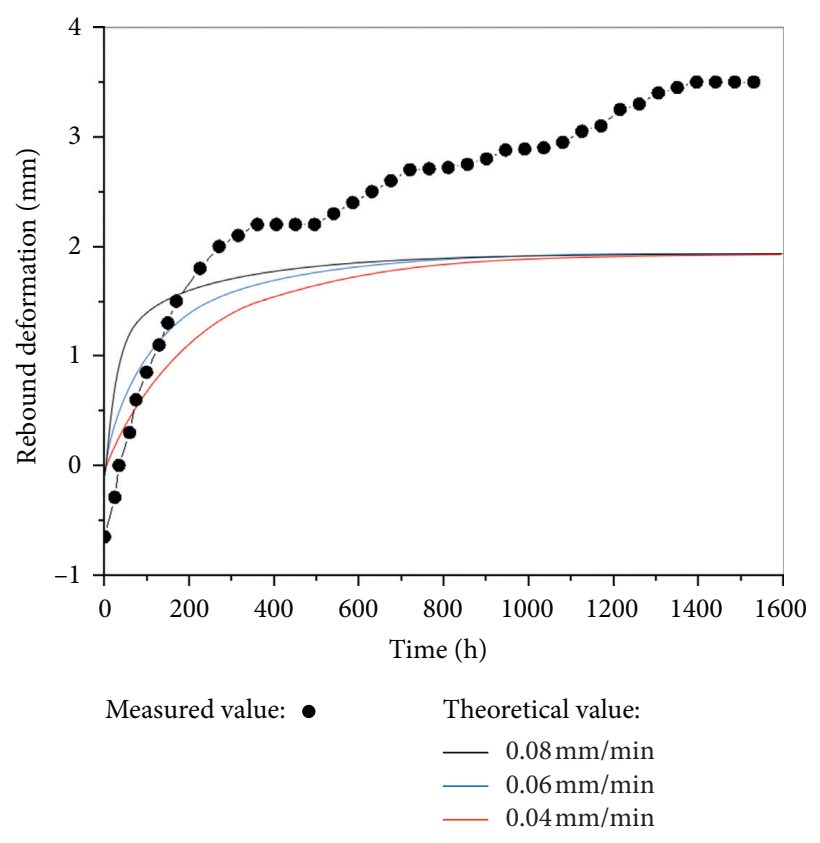

FIGURE 19: Comparison between calculated and measured values of rebound at different unloading rates.

preliminarily considered as the plastic deformation caused by the compaction of the soil around the foundation pit or the buildings on the soil in the pit during the excavation of the foundation pit. However, this rebound deformation was not considered in the equation for the calculation of rebound in this paper. Therefore, the applicability and accuracy of the method for predicting the base rebound generated by unloading remain to be further studied.

\section{Conclusions}

(1) According to the general equation of unidirectional seepage consolidation, the differential equation of seepage consolidation involving the change in external load was obtained. The analytical solution of excess pore water pressure in the seepage consolidation equation applicable to the unloading condition of foundation pit excavation was given. In combination with the principle of effective stress, the equation for calculating the rebound caused by the change in the excess pore water pressure in the soil unloading process was derived.

(2) During the foundation pit excavation in soft clay areas simulated by the triaxial unloading test, the unloading of clayed soil samples produced negative excess pore water pressure. This increased with an increasing unloading rate, and its peak value decreased with an increasing confining pressure. A comparison was made between the test results and the relevant analytical solution of the seepage consolidation equation. It was found that the analytical solution of excess pore water pressure effectively reflected the variation law of the excess pore water pressure during excavation unloading of the foundation pit. 
(3) The study on the soil rebound generated during the change in negative excess pore water pressure found that the rebound gradually decreased with an increasing confining pressure.

(4) A comparison between the theoretical value and the measured values of the rebound deformation found that the theoretical variation law was in good agreement with the measured results, indicating that the equation for the calculation of rebound under unloading has practical engineering significance.

\section{Data Availability}

Some of the experimental test data used to support the findings of this study are included within the article. The other data used to support the findings of this study are available from the corresponding author upon request.

\section{Conflicts of Interest}

The authors declare that there are no conflicts of interest regarding the publication of this paper.

\section{Acknowledgments}

This research was supported by the National Natural Science Foundation of China (Grant no. 51609081).

\section{References}

[1] H. Lei, X. Wang, L. Chen, M. Huang, and J. Han, "Compression characteristics of ultra-soft clays subjected to simulated staged preloading," KSCE Journal of Civil Engineering, vol. 20, no. 2, pp. 718-728, 2016.

[2] G. B. Liu and X. Y. Hou, "Unloading modulus of the Shanghai soft clay," Chinese Journal of Geotechnical Engineering, vol. 18, pp. 18-23, 1996.

[3] G. B. Liu and F. B. Jia, "Test research on time effect of foundation pit rebound," Chinese Journal of Rock Mechanics and Engineering, vol. 26, pp. 3040-3044, 2007.

[4] X. C. Shi and Y. Han, "Water absorption test of soft clay after rebound under unloading," Rock and Soil Mechanics, vol. 31, no. 3 , pp. 732-742, 2010.

[5] C. F. Lin and G. H. Lei, "Responses of negative excess pore water pressure under unloading in one-dimensional swelling tests," Rock and Soil Mechanics, vol. 38, pp. 3613-3618, 2017.

[6] Y. L. Hao and G. Li, "Study on anti-consolidation and rebound behavior of soft ground improved by surcharge preloading after unloading," Chinese Journal of Rock Mechanics and Engineering, vol. 24, pp. 884-886, 2005.

[7] C. X. Li and A. F. Hu, "Semi-analytical solution of one-dimensional consolidation with non-darcian flow considering time-dependent loading," Chinese Journal of Rock Mechanics and Engineering, vol. 30, no. S2, pp. 3937-3943, 2011.

[8] W. B. Wu, G. S. Jiang, M. H. E. l. Naggar, G. X. Mei, M. J. Xu, and R.Z. Liang, "One-dimensional consolidation of soil under multistage load based on continuous drainage boundary," International Journal for Numerical and Analytical Methods in Geomechanics, vol. 44, no. 3, 2020.

[9] J. Zhao and N. Guo, "Unique critical state characteristics in granular media considering fabric anisotropy," Géotechnique, vol. 63, no. 8, pp. 695-704, 2013.
[10] Y. Fu, S. He, S. Zhang, and Y. Yang, "Parameter analysis on hardening soil model of soft soil for foundation pits based on shear rates in shenzhen bay, China," Advances in Materials Science and Engineering, vol. 2020, Article ID 7810918, 2020.

[11] P. N. Singh and W. W. Wallender, "Effects of adsorbed water layer in predicting saturated hydraulic conductivity for clays with kozeny-carman equation," Journal of Geotechnical and Geoenvironmental Engineering, vol. 134, no. 6, pp. 829-836, 2008.

[12] F. N. Dang, H. W. Liu, and X. W. Wang, "Empirical formulas of permeability of clay based on effective pore ratio," Chinese Journal of Rock Mechanics and Engineering, vol. 34, pp. 1909-1917, 2015.

[13] Q. Z. Hu, Q. Zou, and M. Li, "Study on permeability coefficient of cohesive soil based on three-dimensional ideal model of soil parti- cles," Chinese Journal of Science Technology and Engineering, vol. 20, no. 11, pp. 4512-4519, 2020. 